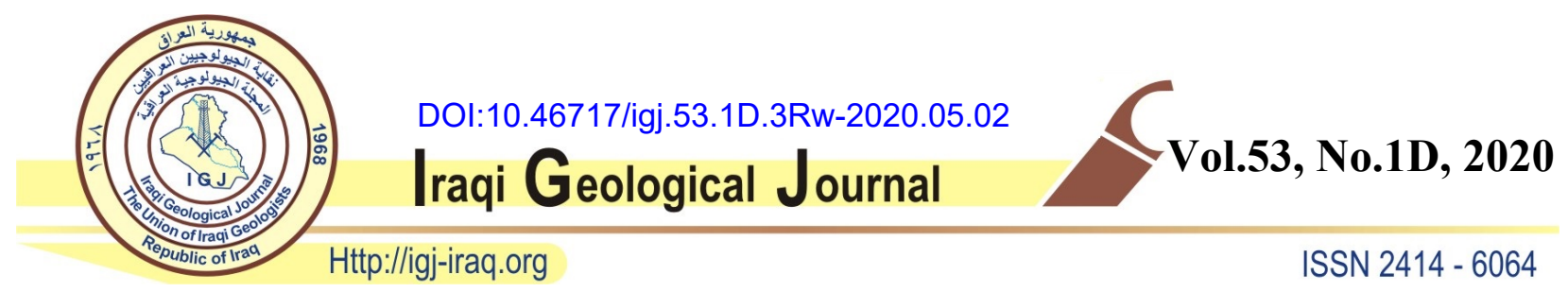

\title{
DETERMINATION OF PORE TYPES AND POROSITY TRENDS USING OF VELOCITY-DEVIATION LOG FOR THE CARBONATE MISHRIF RESERVOIR IN HALFAYA OIL FIELD, SOUTHEAST IRAQ
}

\author{
Buraq Adnan Al-Baldawi \\ Department of Geology, College of Science, University of Baghdad, Baghdad, Iraq \\ E-mail: buraqaddnan@yahoo.com \\ Received: 20 December 2019; accepted: 18 February 2020
}

\begin{abstract}
Halfaya field is located south of Iraq towards southeast Amara city in Missan. Mishrif Formation is a major reservoir in Halfaya Oilfield and is one of the principal carbonate reservoirs in central and southeastern Iraq. The aim of this study is to predict pore types using well logs data at missing core intervals. This study includes calculating the velocity deviation log for the Mishrif carbonate reservoir in two wells in Halfaya oil fields (HF-1 and HF-2) by converting porosity-log data into a synthetic velocity log by means of a time-average equation. A velocity-deviation log, which is calculated by integrating a sonic log with a neutron-porosity or density log, provides a means of obtaining downhole details in carbonates about the major pore forms. These data can be used to track the downhole distribution of diagenetic processes and their effects on secondary porosity trends. The differences are plotted as a velocitydeviation log between the actual sonic log and the synthetic sonic log. These velocity-deviation logs reflect the different physical rock markings of different types of pores: (1) Positive velocity deviations mark areas in which pore types form frames dominate; (2) zero deviations indicate periods in which the rock lacks a rigid frame and exhibits dissolution porosity or microporosity; and (3) Negative deviations mark areas in which sonic velocities are remarkably low due to cavernous borehole walls, fractures or possibly high free-gas content.
\end{abstract}

Keywords: Mishrif Formation; Halfaya Oilfield; Velocity-deviation log; Porosity types

\section{INTRODUCTION}

Carbonate sediments and rocks are characterized by a broad range of physical properties which are affected by variable deposition and diagenesis. It is more difficult than in silica sediments to 
determine physical properties from known lithology, age or depth of burial where physical properties, such as velocity and porosity, follow a more regular pattern of hole (Hamilton, 1980).

Nevertheless, the prediction of carbonate lithology is easy when the values and distribution of physical properties are known, given the broad spectrum and sensitivity of measured parameters to lithological alterations. Wireline logs are the most powerful tool for forecasting downhole lithology in drill holes that have not been regularly cored and physical. This study shows how knowledge of the porosity-velocity association in carbonates can be used to establish wireline-log interpretation by predicting other parameters, such as pore size, diagenesis, and porosity patterns, in addition to parameters measured by wireline. The study deals with the velocity-porosity relationship in carbonate where these petrophysical properties help a more regular downhole pattern. This study shows how velocity-porosity correlations can be used to develop wireline-log interpretation by apportioning prediction of other parameters such as pore type, the extent of diagenesis and porosity trends.

\section{THE STUDY AREA}

The Halfaya field is located south of Iraq in Missan, 35 kilometers southeast Amara city (Fig.1). Halfaya field is situated in the southern part of the Mesopotamia, foredeep of the eastern unstable continental shelf bordered to the east by Zagross Fold Belt where the burial depth is the deepest, the thickness of sedimentary is the largest and the structure is the most stable (Hamdan, 2011).

\section{GEOLOGICAL SETTING}

Mishrif Formation was deposited in the secondary (Cenomanian-early Turonian) sedimentary phase, which was widespread throughout the Arabian Gulf during the Cretaceous period. Mishrif Formation is a carbonate series represented by oxidized shallow open marine carbonates. Various diagenic processes involving porosity and permeability have been affected (Burchett, 1993).

The Late Cenomanian to Early Turonian was a period of generally favorable conditions for high organic productivity worldwide and the eustasy was the main element controlling the growth, development and location of the buildings (Van Buchem et al., 2002). The Mishrif is composed of two major sedimentary cycles abruptly terminated by the unconformity which separates the Mishrif from the overlying Khasib Formation (Aqrawi et al., 2010). The equivalent formations of the Mishrif Formation are Gir-bir Formation in the North and the Balambo Formation of the deeper eastern and intrabasinal part of the same basin of the Dokan Formation (Aqrawi et al., 2010). 


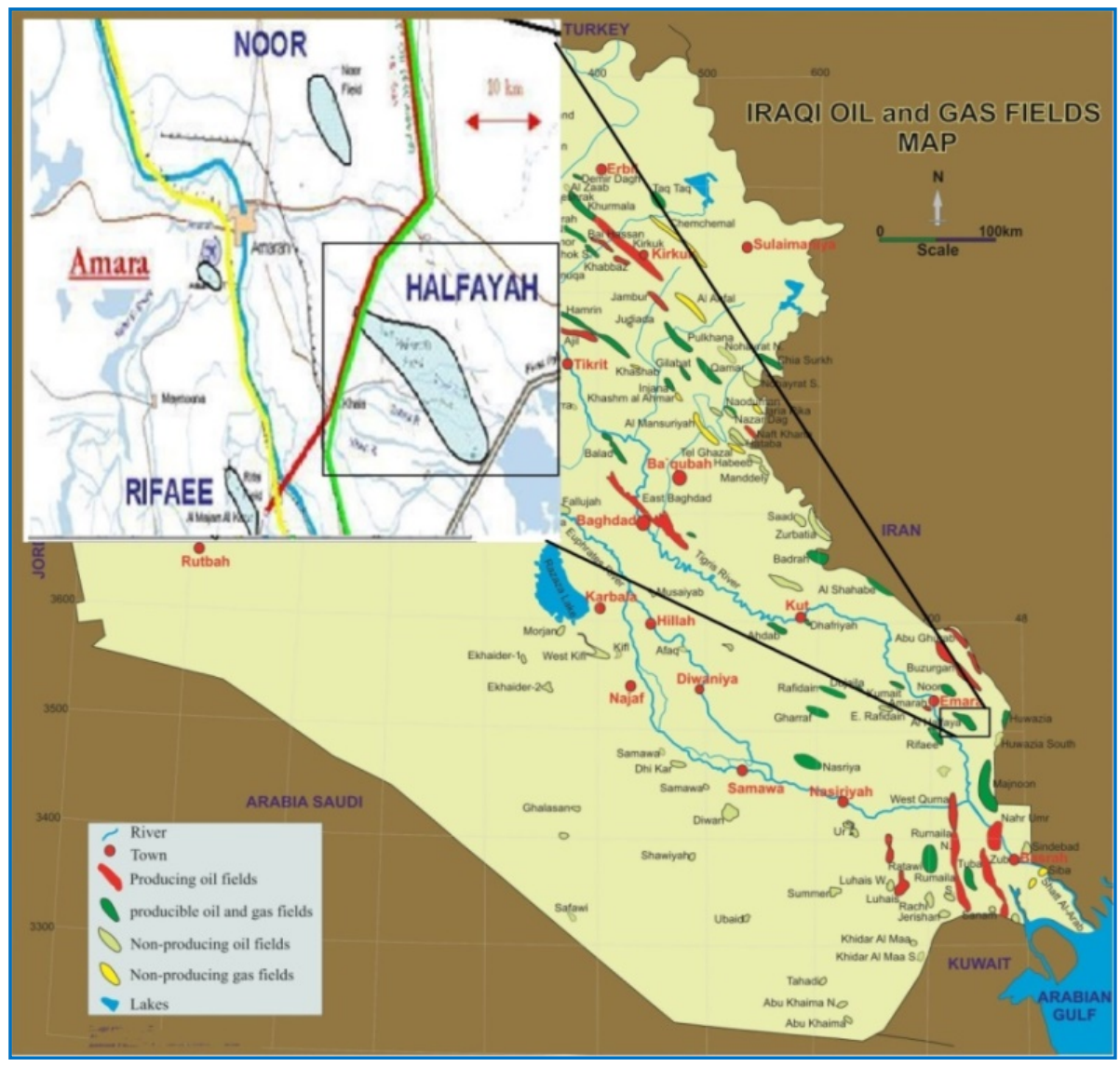

Fig. 1. Location map of the study area (modified from Al-Khafaji et al., 2013)

The lower boundary of Mishrif Formation represents the change from basinal Rumaila Formation to shallow open marine facies It is a conformable surface. The upper boundary with the Khassib Formation is truncated by an unconformity surface separating the Middle from Late Cretaceous (Aqrawi et al., 2010).

\section{MATERIALS AND METHODS}

This study was performed on two wells of Halfaya Field (HF-1and HF-2). As a first step, the available logs (Neutron, Density, Sonic, and Gamma-Ray) are scanned and digitized. One reading per $0.25 \mathrm{~m}$ depth is selected for recording the input data measurements, which is used in this study. The digital reading of all variables of the well logs for both boreholes (studied wells) has been prepared by the author. By using Interactive Petrophysics Program the interpretations are made (an interactive program to carry out interpretations and log corrections for borehole environment and invasion effects), the corrected log sets are used as input data to evaluate the carbonate rocks (Mishrif Formation) for the wells under study. At the beginning of this work we need determination the lithology and total porosity as quick lock method of formation that is 
shown in Figures $(2 \& 3)$, which represents one of the basic methods of quantitative interpretations of the neutron-density cross plot, the majorities of the points are calcite limestone and indicate good porosity resolution, good lithological resolution of limestone which indicated on the lithology of Mishrif Formation is limestone and total porosity ranges between 0-27\%.

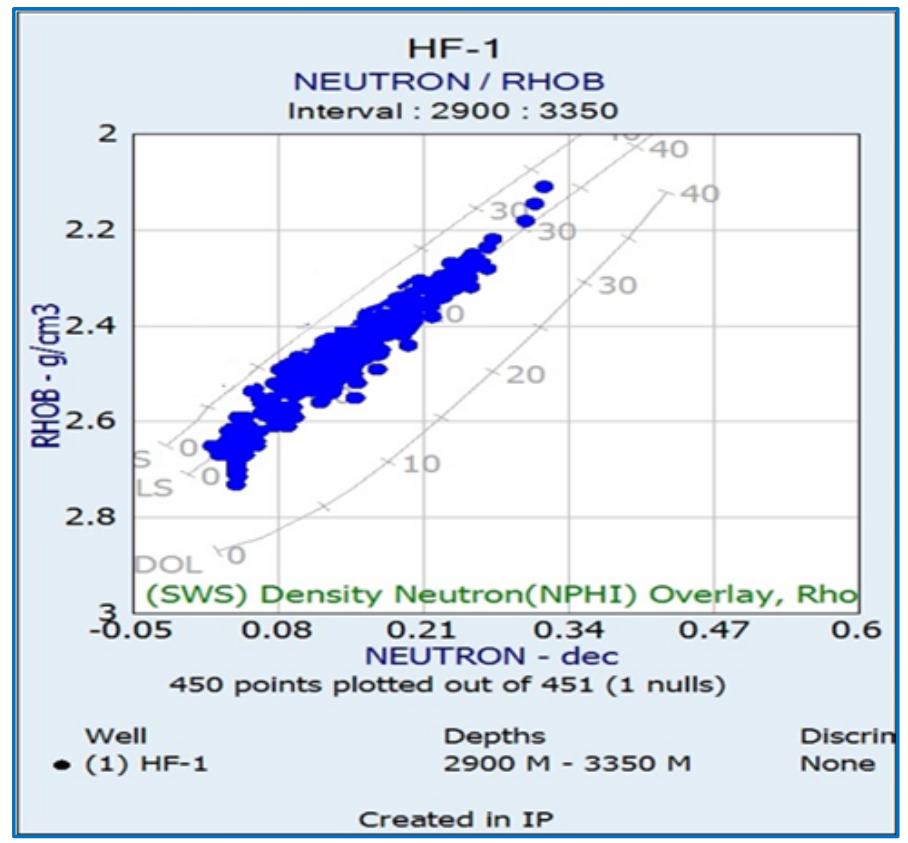

Fig. 2. Neutron density cross plot in well HF-1

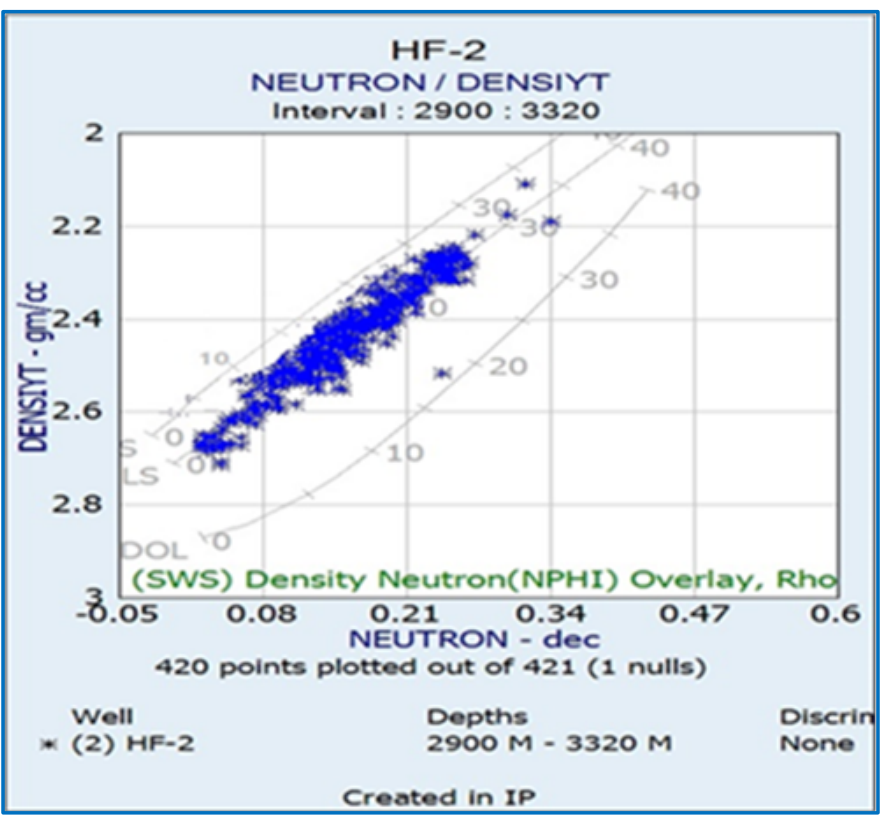

Fig. 3. Neutron density crossplot in well HF-2 
The velocity-deviation log is calculated by comparing details about porosity and velocity from wireline-log data. From the sonic log, velocity data are obtained that measure transit times through a short vertical rock interval. Sonic log velocity can be set or computed by:$\mathrm{VP}=1000000 /$ sonic log read (DT) (Schlumberger, 1972)

A cross plot of porosity vs. Vp (Figs. 4-7) displays a distinct inverse trend, where velocity decreases with increasing porosity. $V p$ of all analyzed samples for studied wells ranged between 1900 and $6200 \mathrm{~m} / \mathrm{s}$, documenting the wide range of velocities in carbonates. Porosity values ranged between 0 and $35 \%$. Measured velocities can be compared with those calculated from the time-average equation of Wyllie et al. (1956),

$\frac{1}{v \text { rock }}=\frac{(1-\emptyset)}{v \text { matrix }}+\frac{\emptyset}{v \text { fluid }}$

Where:

$\mathrm{V}$ rock $=$ velocity of limestone rock

Vmatrix $=6530 \mathrm{~m} / \mathrm{s}$ (Velocity deviation of calcite)

Vfluid $=1500 \mathrm{~m} / \mathrm{s}$ (Velocity deviation of fluid (water)

Porosity values are obtained from the neutron porosity log or by the density log where the neutron-porosity $\log$ is not available, the density $\log$ can be used. In the following section, we explain both methods for calculating the velocity-deviation log.

\section{A. Determination from Neutron Porosity and Sonic Log}

A uniform synthetic velocity log is determined from the neutron-porosity log-measured porosity values for well HF-1 (Fig.8) and for well HF-2 (Fig.9). These velocity values are the values expected from the porosity value, depending on the porosity-velocity conversion being used. Porosity values are usually translated to velocity by applying the time-average equation (Wyllie et al., 1956). Additionally, another porosity-velocity equation, such as the best-fit curve, can be used through any given data set. You can equate the measured synthetic velocity log to the true velocities obtained from the sonic log. Subtracting the velocity values of the synthetic sonic log from the velocity values determined from the true sonic log obtains the velocity deviations.

(Velocity deviation $=$ sonic log velocity - velocity calculated from neutron-porosity or density $\log )$. (3).

These velocity deviations can be plotted as normal log data in plots of deviation vs. depth. The best graphical displays were made by filling the deviations in regard to the zero-deviation line. 


\section{B. Determination from Density Porosity and Sonic Log}

The density log may be used to construct the synthetic velocity log, Figure (10) for well HF-1 and Figure (11) for well HF-2, in cases where the neutron-porosity log is not available. In our case study, this technique had to be done in zones where the neutron porosity log did not show any readings. The porosity of the density log is calculated from the bulk density of the clean liquid-filled deposits, when the matrix density of the saturated fluids and the density of the saturated fluids are known after the shale effect has been reversed. (Asquith and Krygowski, 2004):

$\emptyset \mathrm{D}=\rho \mathrm{ma}-\rho \mathrm{b}) /(\rho \mathrm{ma}-\rho \mathrm{f})$

Where: $\emptyset \mathrm{D}=$ porosity by Density $\log$.

$\rho m a=$ Density of the dry rock $\left(\mathrm{g} / \mathrm{cm}^{3}\right)$ in this study $=2.71\left(\mathrm{~g} / \mathrm{cm}^{3}\right)$ from limestone formation .

$\rho f=$ Density of fluid $\left(\mathrm{g} / \mathrm{cm}^{3}\right)=1 \mathrm{~g} / \mathrm{cm} 3$ for fresh water or $1.1 \mathrm{~g} / \mathrm{cm}^{3}$ for salt mud.

$\rho b=$ bulk density recorder by log.

A comparison of the two methods displays the velocity-deviation log for the same drill hole using either the porosity or the density logs. This comparison shows that in all sections of the two wells under study the trends of velocity deviations that calculated from neutron porosity appear mainly as a shift toward higher values than deviations when the density log is used.

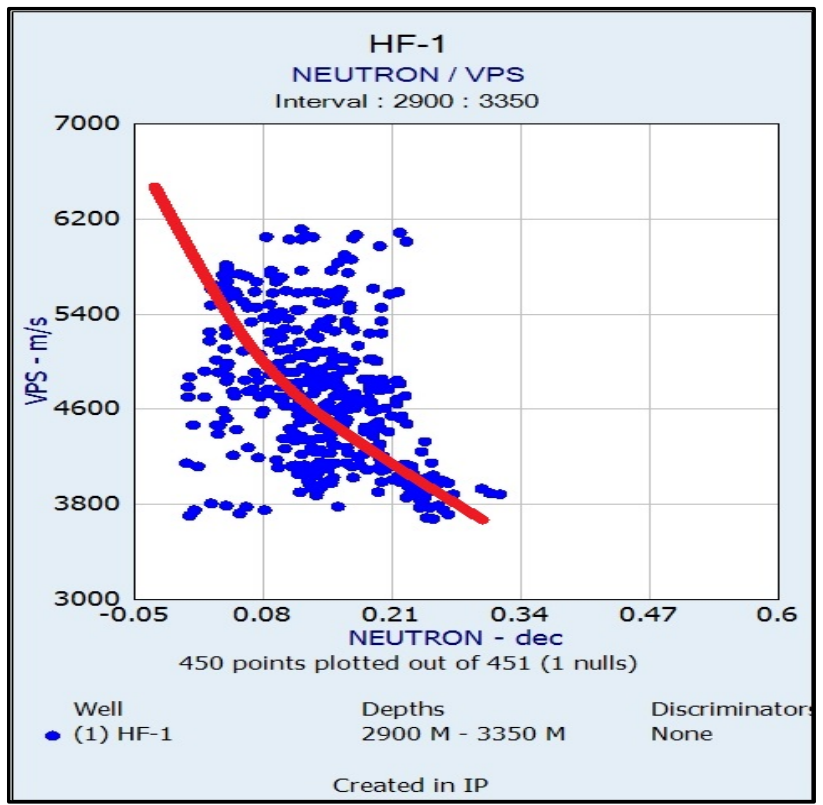

Fig. 4. Cross plot of Vps and neutron porosity in well HF-1 


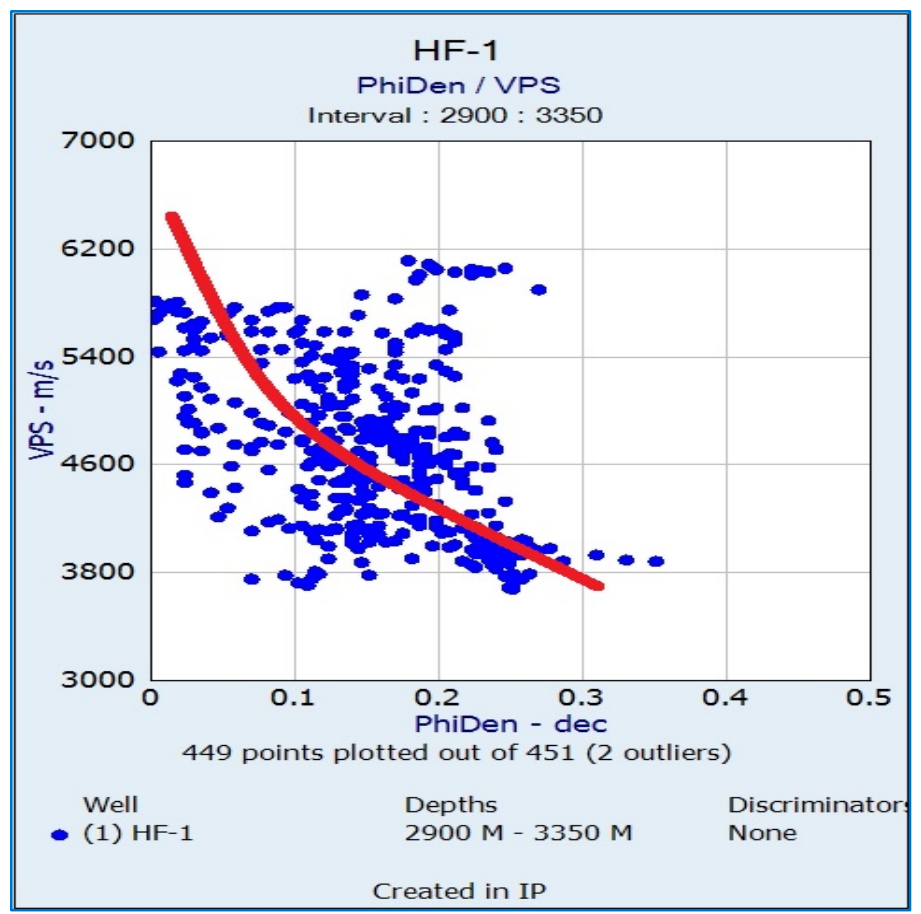

Fig. 5. Cross plot of Vps and density porosity in well HF-1

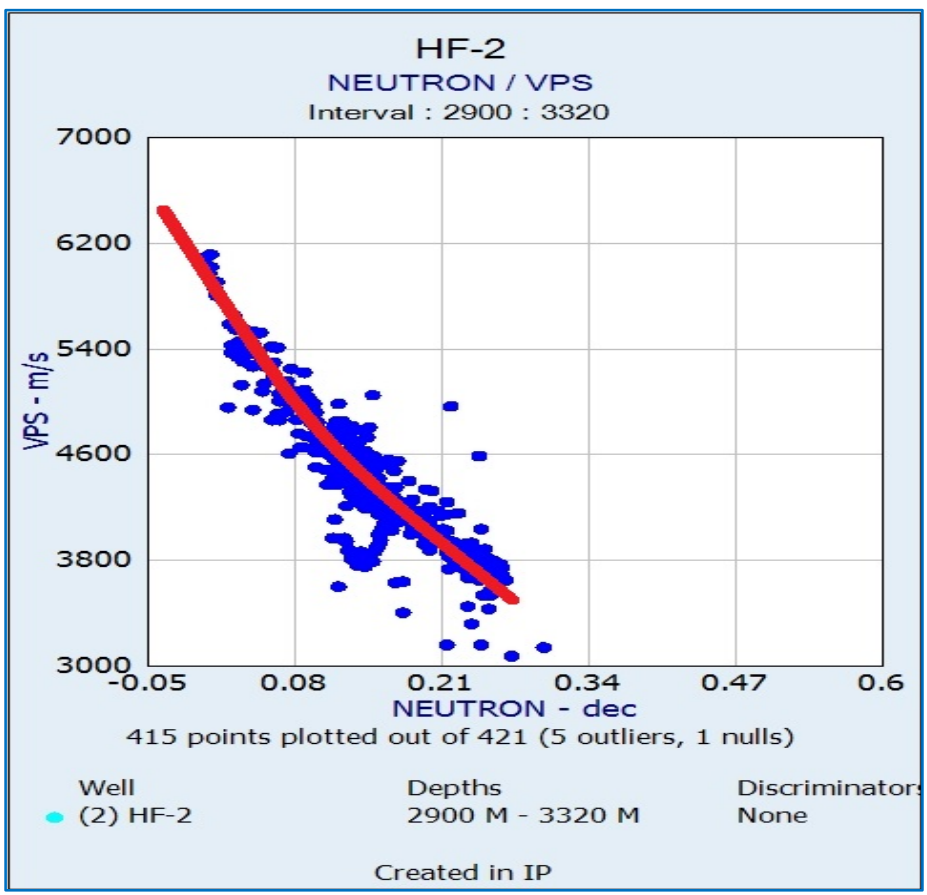

Fig. 6. Cross plot of Vps and neutron porosity in well HF-2 


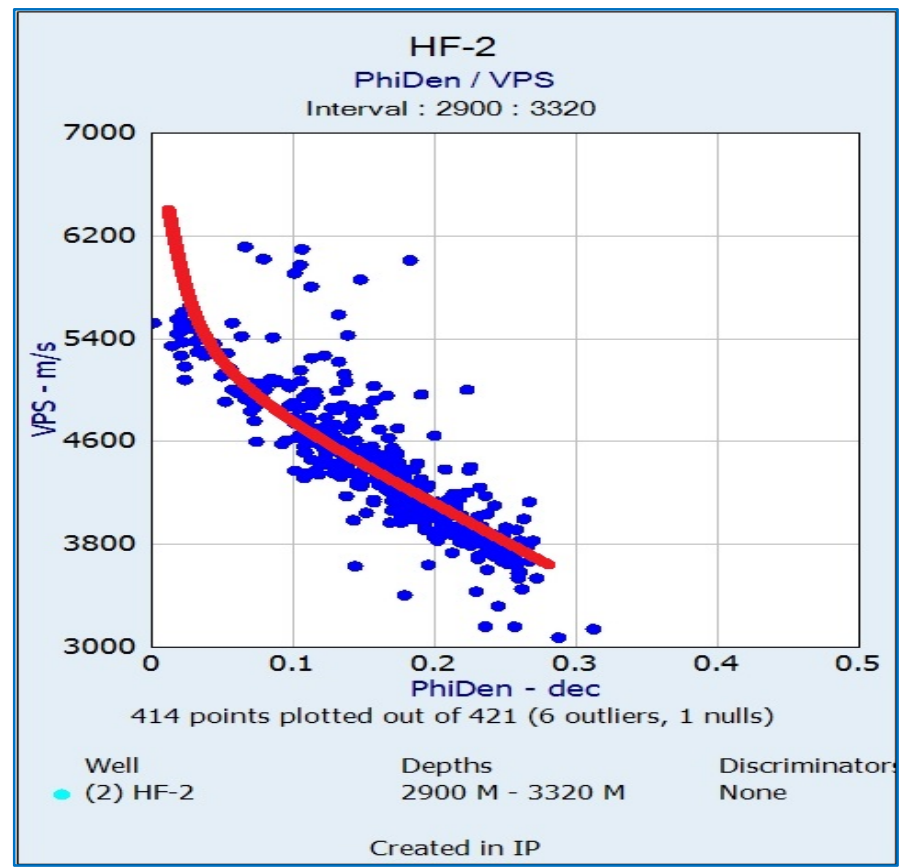

Fig. 7. Cross plot of Vps and density porosity in well HF-2

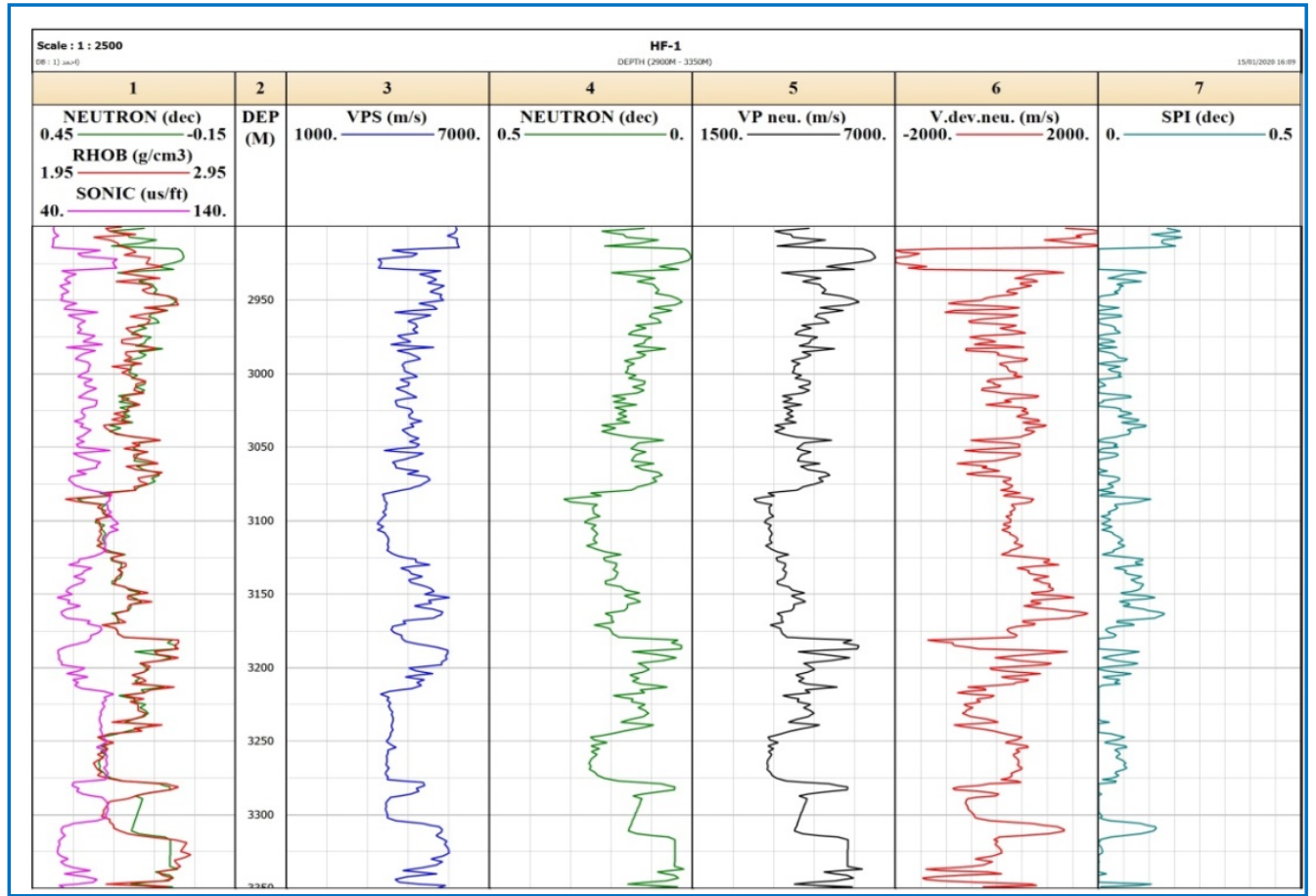

Fig. 8. Velocity-Deviation log and porosity trends of well HF-1 using neutron porosity 


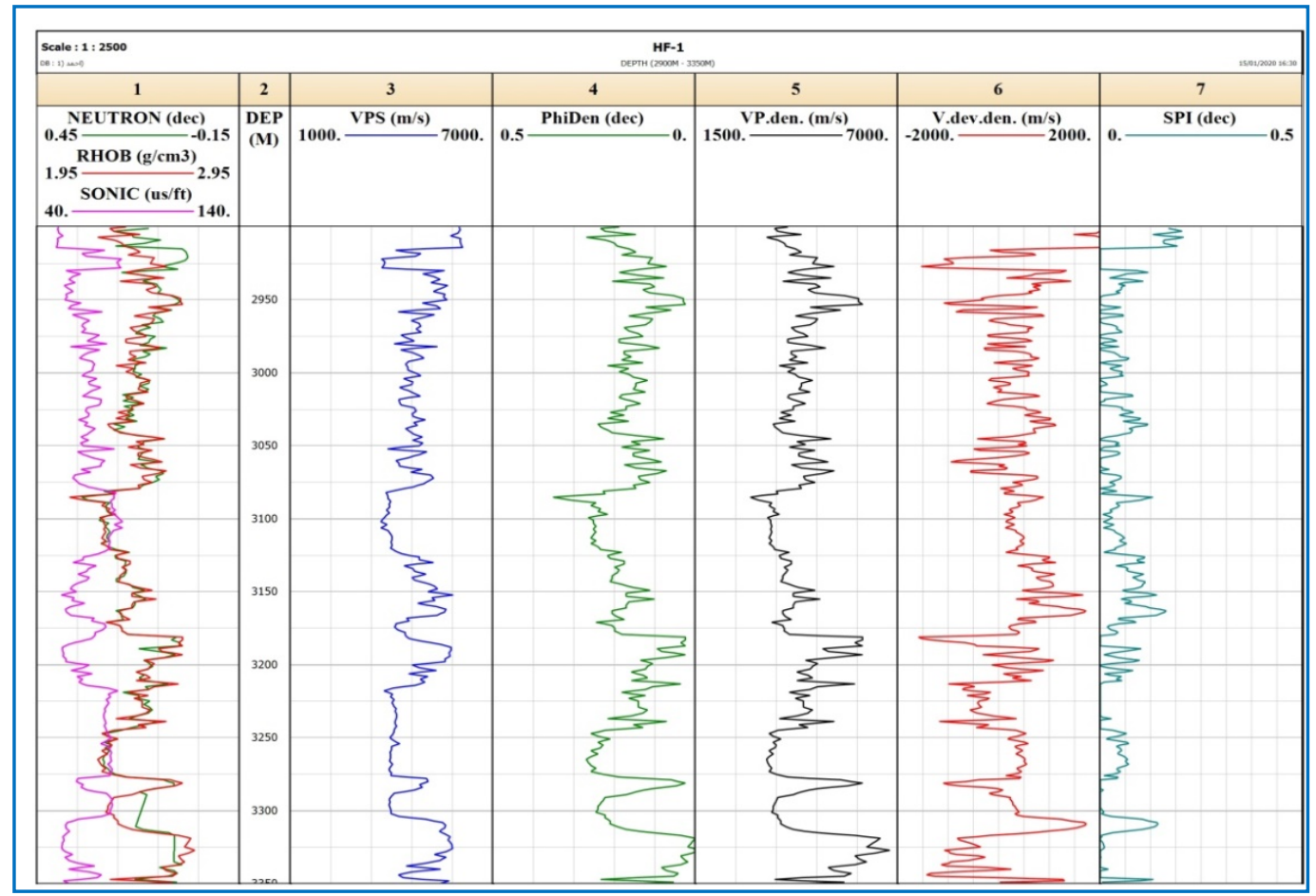

Fig. 9. Velocity-Deviation log and porosity trends of well HF-1 using density porosity

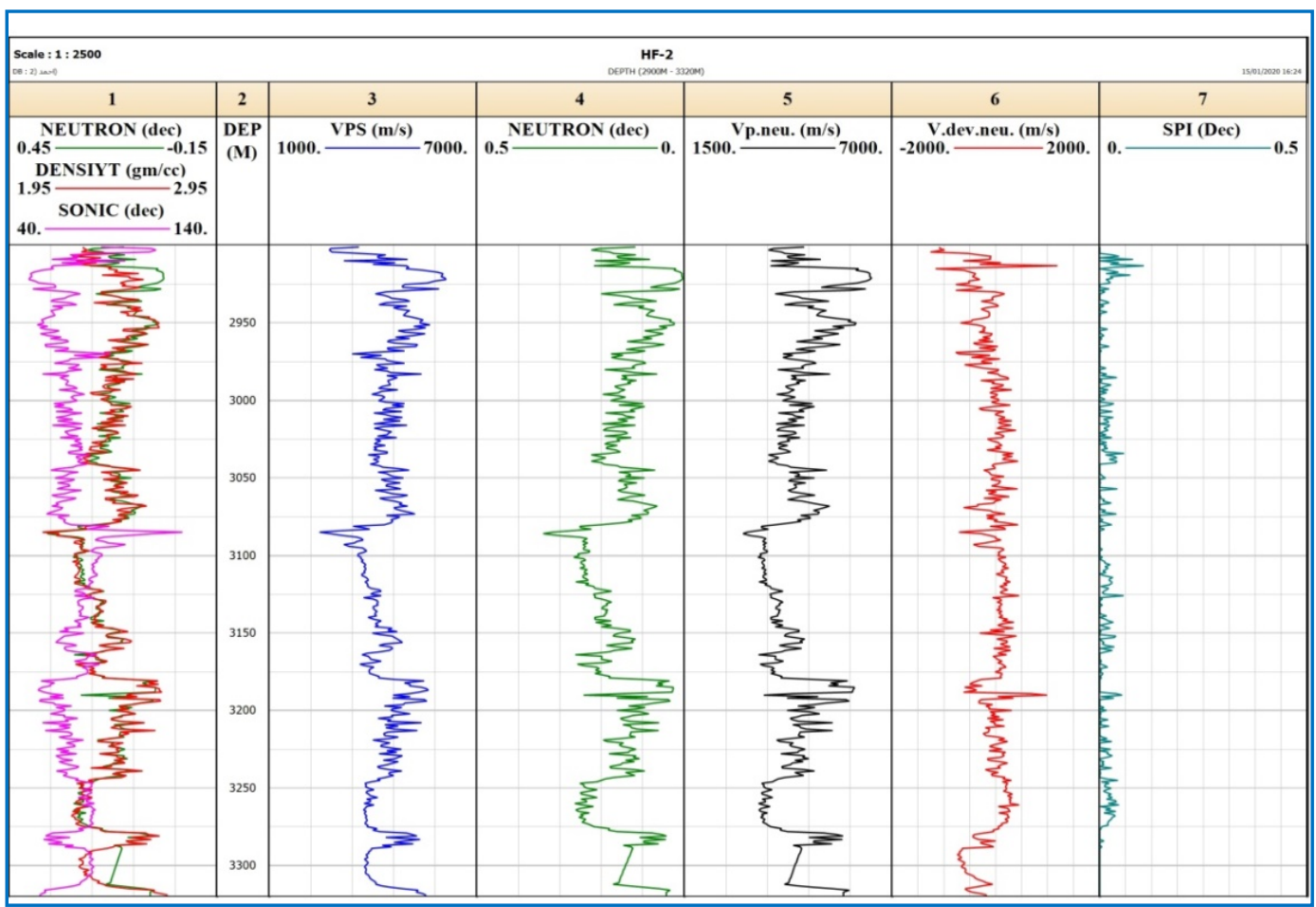

Fig. 10. Velocity-Deviation log and porosity trends of well HF-2 using neutron porosity 


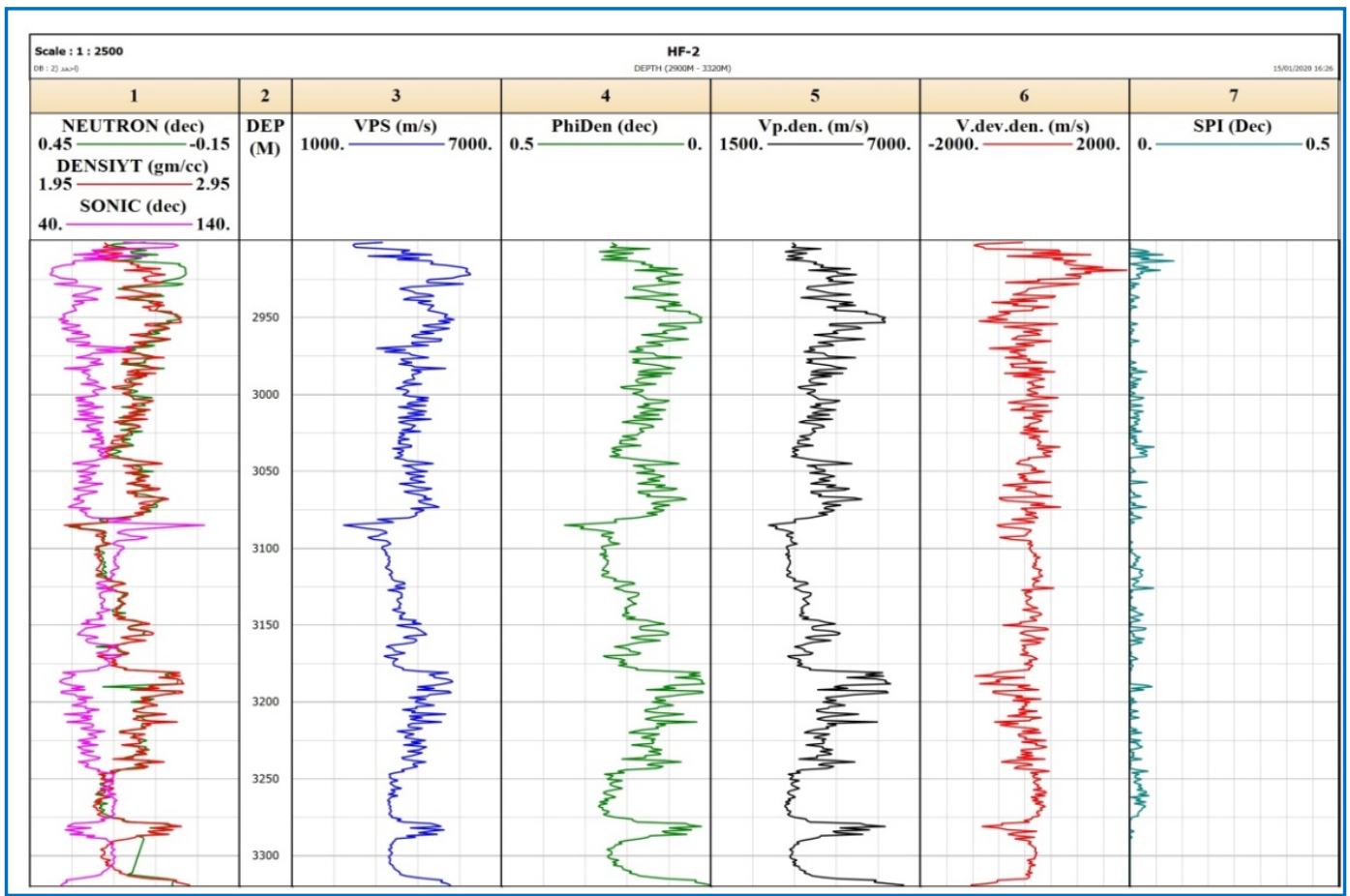

Fig. 11. Velocity-Deviation log and porosity trends of well HF-2 using density porosity

\section{GENERAL INTERPRETATION}

The following statements are standard interpretations which are concluded by Anselmetti and Eberl (1999) and then depended and linked with the results of the current study:

1. The positive deviation indicates relatively high velocity in porosity where the pores are not commonly connected, such as in interafossils or porosity of moldi and vuggy. Positive deviations may also indicate low permeability but increase in secondary porosity (Anselmetti and Eberli, 1999).

2. Zone with \pm zero deviation. Zero with small variance $( \pm 500 \mathrm{~m} / \mathrm{s})$ or less reflect segment that fits the predictions of the average time equation, zone is dominated by either interparticle, intercrystalline or high micro porosity. All of these types of pores predominate particularly in dolomites or carbonates that just after deposition. The majority of the zone has a small velocity deviation; this indicates areas with small diagenetic changes and increases in primary porosity and very low secondary porosity (Anselmetti and Eberli, 1999).

3. Zone with Negative Deviation: There are three possibilities of the Negative Deviation zone.

a. Caving or irregularities of the borehole wall. 
b. Despite the fact that fracture porosity has always been included in secondary porosity.

c. Negative deviation could also be caused by a high free gas content (Excluded in this case) which would have a strong negative impact on the deviation log because gas reduces VP dramatically (Anselmetti and Eberli, 1999) and results in a reduced neutron porosity reading due to the lower content of hydrogen in the fluid phase (Hilchie, 1982). Both of these effects theoretically cause a strong negative signal in the deviation log.

\section{RESULTS AND DISCUSSIONS}

HF-1 well shows that the well is characterized by positive velocity-deviation especially from depth $2950 \mathrm{~m}$ and in more intervals of Mishrif Formation. This indicates that the porosity maybe due to interafossils or moldic and vuggy porosity. These pore types indicate increasing of secondary porosity (Fig. 8). The interval from upper contact of Mishrif Formation to the depth $2950 \mathrm{~m}$ is characterized by negative velocity-deviation values which indicate that the porosity maybe due to caving or irregularities of the pore holes or maybe fracture porosity as shown in figure (9) that velocity-deviation log is calculated from density log.

Figures $(10 \& 11)$ of HF-2 well show that the well is characterized by a small velocity deviation in most the intervals of the formation. The zone of Zero with small deviation ( \pm 500 $\mathrm{m} / \mathrm{s}$ ) or less represent section are dominated by either interparticle, intercrystalline or high micro porosity which indicate zones with little diagenetic alterations and increases of primary porosity and very low secondary porosity. The table 1 shows minimum, maximum and average of total porosity (PHIT) and secondary porosity index (SPI) for Mishrif Formation using well logs data. This table illustrates the variation of porosity due to secondary porosity when the velocity deviation $\log$ increases or decreases.

Table 1. Total and secondary porosity indices

\begin{tabular}{|l|c|c|c|c|c|c|}
\hline \multicolumn{1}{|c|}{ Wells } & \multicolumn{3}{c|}{ PHI } & \multicolumn{3}{c|}{ SPI } \\
\hline & \multicolumn{1}{|c|}{ Min } & Max & Av & Min & Max & Av \\
\hline Hf-1 & 0.033 & 0.345 & 0.158 & 0 & 0.206 & 0.028 \\
\hline HF-2 & 00.025 & 0.343 & 0.161 & 0 & 0.107 & 0.013 \\
\hline
\end{tabular}

\section{CONCLUSIONS}

Acoustic velocity in carbonate is a complex feature of porosity and pore forms that are influenced by the lithology and diagenetic alteration combined effects. The presence of various pore forms in carbonate Mishrif Formation causes significant dispersion in the velocity-porosity diagram, 
and most samples show variations from the normal velocity-porosity pattern. The term ' velocity variance' is defined as the difference between the measured acoustic velocity and the velocity calculated from the measured porosity by applying the widely used empirical time-average equation.

Positive deviations occur from higher than expected low velocity values of a given porosity and are characteristic of pores types in a rock frame that have high elastic properties of a material. This type of porosity is characterized by low permeability due to most of these pores are not connected, but rather are separated by a densely cemented matrix inhibiting major fluid flow through the isolated pores. A zero velocity deviation is typical of interparticle, intercrystalline or high micro porosity; this type of porosity has high permeability and low secondary porosity. The negative velocity deviations indicate caving or irregularities of the borehole wall or high content of free gas with very low secondary porosity (mostly negative values).

\section{REFERENCES}

Al-Khafaji, A., Al-Ameri, T., Abeed, Q., 2013. Oil and gas play and prospect assessments of Babel, Diwania and Karbala Governorates Middle Euphrates Region), Iraq. Arab J Geosci. (On line first) doi:10.1007/s12517013-0980-8.

Anselmetti, F. S. and Eberli, G. P., 1999. The velocity-deviation log: A tool to predict pore type and permeability trend in carbonate drill holes from sonic and porosity or density logs: AAPG Bulletin, 83(3): 450-466.

Aqrawi, A. A. M., Goff, J. C., Horbury, A. D., and Sadooni, F. N., 2010, The Petroleum Geology of Iraq: Scientific Press, $424 \mathrm{p}$.

Asquith, G. B., and Krygowski, D., 2004. Basic Well Log Analysis, 2nd Edition: AAPG Methods in Exploration Series 16. Published by The American Association of Petroleum Geologists Tulsa, Oklahoma, 244p.

Burchett, T. P., 1993. Mishrif Formation (Cenomanian-Turonian), southern Arabian Gulf: carbonate platform growth along cratonic basin margin, in Simo, J.A.T., Scott, R. W., and Masse, J. P. (eds.), Cretaceous carbonate platforms. AAPG Memoir, 56:185-199.

Hamdan, W. L., 2011. Petrel software modeling of the Mishrif Formation in Buzurgan Field. Unpublished M.Sc. Thesis, University of Baghdad.

Hamilton, E. L., 1980. Geoacoustic modeling of the sea-floor: Journal of the Acoustical Society of America, 68:1313-1340.

Hilchie, D. W., 1982. Advanced well log interpretation: Golden, Colorado, D.W. Hilchie, variously paginated.

Schlumberger, 1972. Log interpretation-principles: New York, Sclumberger Limited, 1: 113.

Van Buchem, F. S. P., Razin, P., Homewood, P. W., Oterdoom, W. H., and Philip, J. M., 2002. Stratigraphic organization of carbonate ramps and organic-rich intrashelf basins: Natih Formation (middle Cretaceous) of northern Oman. AAPG Bulletin, 86:21-53.

Wyllie, M. R., Gregory, A. R., and Gardner, G. H. F., 1956. Elastic wave velocities in heterogeneous and porous media: Geophysics, 21(1): 41-70. 